\title{
Coulisses
}

Revue de théâtre

19 | Hiver 1999

Varia

\section{Hommage à Béatrice Perregaux}

Éric Eigenmann

\section{(2) OpenEdition}

Journals

Édition électronique

URL : https://journals.openedition.org/coulisses/5705

DOI : $10.4000 /$ coulisses. 5705

ISSN : 2546-9460

\section{Éditeur}

Presses universitaires de Franche-Comté

\section{Édition imprimée}

Date de publication : 1 janvier 1999

Pagination : 60

ISBN : 2-913322-09-3

ISSN : $1150-594 X$

\section{Référence électronique}

Éric Eigenmann, « Hommage à Béatrice Perregaux », Coulisses [En ligne], 19 | Hiver 1999, mis en ligne le 18 octobre 2019, consulté le 12 janvier 2022. URL : http://journals.openedition.org/coulisses/5705 ; DOI : https://doi.org/10.4000/coulisses.5705

Ce document a été généré automatiquement le 12 janvier 2022.

Coulisses 


\title{
Hommage à Béatrice Perregaux
}

\author{
Éric Eigenmann
}

Le Théâtre Universitaire de Franche-Comté a rencontré Béatrice Perregaux lorsqu'il a présenté Électre 90 dans le cadre d'une journée d'études sur le théâtre antique à l'Université de Neuchâtel. La pertinence et la générosité de ses critiques vis-à-vis de notre travail avaient suscité chez nous tous une vive émotion. Par ailleurs, tous les non-germanophones ont été amenés à travailler sur les traductions de Brecht aux Éditions de L'Arche. C'est pourquoi Coulisses s'associe à cet hommage.

1 Il n'est pas facile de s'imposer à la fois sur la scène universitaire et sur les planches. Béatrice Perregaux y était parvenue, qui s'est éteinte le 18 mars 1998 à l'âge de 61 ans.

2 Ses premières reconnaissances officielles dans l'un et l'autre domaines, elle les obtint d'ailleurs la même année, en 1959 : la licence ès lettres de l'Université de Genève, avec un mémoire consacré à l'œuvre de Saint-John Perse, et le diplôme d'art dramatique du Conservatoire de la même ville, classe de Greta Prozor, accompagné d'un deuxième prix d'interprétation. Tout en suivant les cours de Jacques Schérer à la Sorbonne, Béatrice Perregaux approfondit ensuite son métier de comédienne, surtout en France. Elle joue des rôles importants : la mère dans Les Fusils de la Mère Carrar de Brecht mise en scène par André Steiger, Athalie dans la pièce éponyme de Racine mise en scène par Jean Bard, la mère encore dans Noces de Sang de Lorca mise en scène par Ariane Mnouchkine. Entre 1962 et 1964, elle accomplit de nouvelles études, de Theaterwissenschaft et de Germanistik à la Freie Universität de Berlin, et assume la fonction de dramaturge à la Volksbühne pour un spectacle de Benno Besson.

3 C'est en 1965 que le professeur Jean Rousset l'appelle comme assistante de littérature française à l'Université de Genève, la chargeant de faire porter l'accent de ses cours et séminaires, lorsque le sujet s'y prête, sur le point de vue dramaturgique. Pour la première fois en Suisse, l'université s'ouvre aux études théâtrales. Or Béatrice Perregaux relève si bien le défi que l'enseignement de "dramaturgie " est bientôt reconnu en tant que tel, puis nommément inscrit au programme dès le semestre d'été 1976. Entre-temps, elle a été nommée chargée d'enseignement, puis chargée de cours en dramaturgie et en histoire du théâtre. On connaît mieux la suite, son autorité auprès des gens de théâtre, des universitaires, des journalistes, qui sollicitent sa collaboration. 
Invitée plusieurs semestres aux Universités de Lausanne, de Neuchâtel et de Berne, présidente de la Société Suisse du Théâtre, membre du conseil de fondation de la Collection Suisse $\mathrm{du}$ Théâtre, membre du comité exécutif de la Fédération Internationale pour la Recherche Théatrale, elle œuvre infatigablement pour le rayonnement, le rapprochement et la collaboration des professionnels de l'art dramatique. Si la relation humaine prime à ses yeux la fonction professorale, celle-ci consiste à nourrir les échanges entre l'académie et la cité, entre la recherche savante et la création artistique.

4 Au chapitre de ses publications se détachent, aux éditions de L'Arche et de Minuit à Paris, ses traductions de l'allemand. Toutes tiennent lieu de référence, qu'il s'agisse des écrits théoriques de Brecht et de Manfred Wekwerth ou des textes dramatiques de Heiner Müller et de Botho Strauss. Elles ne devraient toutefois pas occulter - outre l'ouvrage collectif dirigé avec Louis Naef, Visions - une trentaine d'articles trop discrets, admirables d'intuition, de clarté et de probité intellectuelle, qui s'efforcent toujours de trouver l'expression la plus directe; ascète de l'écriture, Béatrice Perregaux pourchassait la poudre aux yeux conceptuelle comme l'enflure stylistique. En vérité, elle tenait beaucoup de Socrate : elle préférait cultiver le dialogue vivant, a fortiori au sujet d'un événement éphémère tel que le théâtre, et se dévouait en priorité aux causes altruistes, celles de ses étudiants en particulier.

Ses enseignements - qui couvraient toute l'histoire du théâtre des origines à nos jours ! - font figure de pionniers : ouverts très tôt à l'interdisciplinarité, attentifs aux conditions socio-historiques de la production artistique, confrontant la littérature à la représentation théâtrale, à la musique et à l'opéra, ils alliaient les réflexions théoriques aux exercices pratiques, sinon sur scène du moins dans la salle, fût-elle à des centaines de kilomètres de Genève ; ou encore devant l'écran, grâce aux diapositives et, plus tard, aux enregistrements vidéo. Spectatrice émerveillée de Vilar et de Planchon, du Berliner Ensemble et de Strehler, de Chéreau et de Rochaix, aimant le théâtre qui construit sous nos yeux une vision du monde, elle avait à cœur d'offrir aux autres de semblables émotions.

Béatrice Perregaux habitait de sa forte présence les lieux où elle se trouvait : maintien de danseuse classique, tête haute et visage mobile, œil attentif, voire scrutateur, voix tonique et un peu rauque, diction soutenue - présence théâtrale, forcément... De sa présence fidèle, elle habite désormais la pensée de ceux qui ont eu la bonne fortune de recevoir en partage ses connaissances, mais aussi l'énergie de ses enthousiasmes et de ses révoltes. Elle leur aura donné le plus précieux des viatiques. 
Béatrice Perregaux

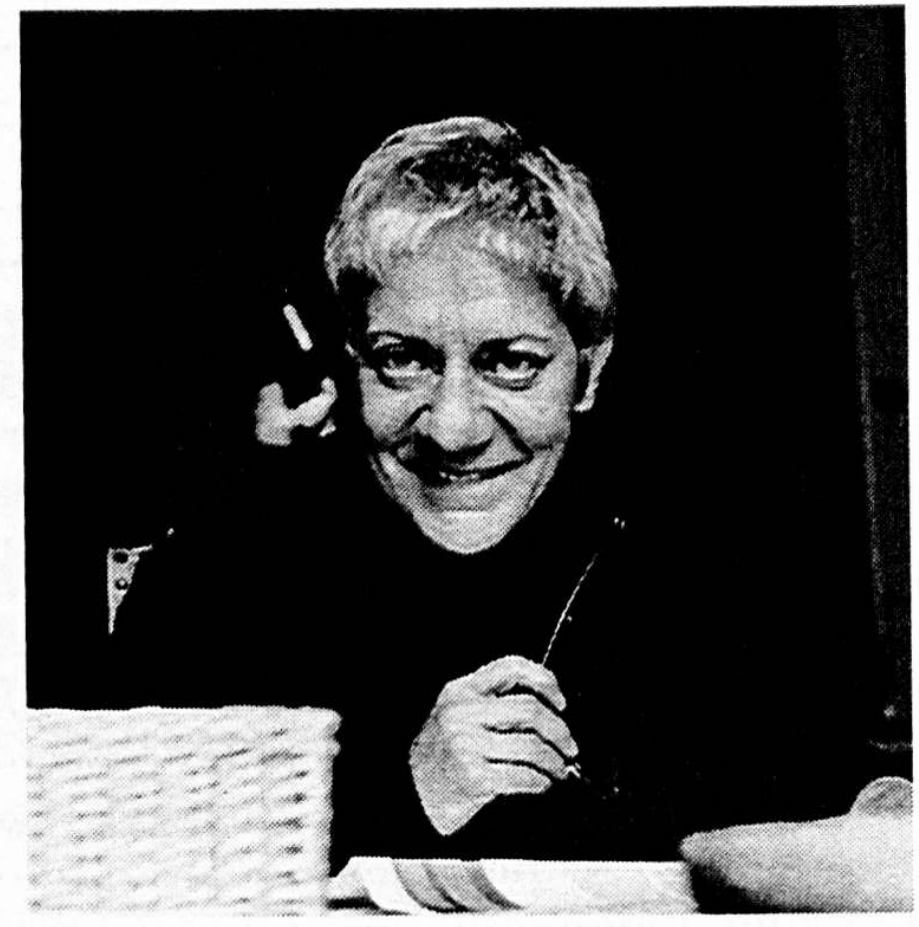

AUTEUR

ÉRIC EIGENMANN

Université de Genève 